\title{
Caracterização antigênica e fenotípica de cepas de Pasteurella multocida isoladas de pulmões de suínos com pneumonia e/ou pleurite ${ }^{1}$
}

\author{
Sandra M. Borowski ${ }^{2}$, Nilo Ikuta ${ }^{3,4}$, Vagner Lunge ${ }^{3,4}$, André Fonseca ${ }^{3}$, Edmundo \\ Marques $^{4}$ e Marisa Cardoso 5
}

\begin{abstract}
Borowski S.M., Ikuta N., Lunge V., Fonseca A., Marques E. \& Cardoso M. 2002. [Antigenic and phenotypic characterization of Pasteurella multocida strains isolated from the lungs of pigs with pneumonia and/or pleuritic lesions.] Caracterização antigênica e fenotípica de cepas de Pasteurella multocida isoladas de pulmões de suínos com pneumonia e/ou pleurite. Pesquisa Veterinária Brasileira 22(3):97-103. Centro de Pesquisas Veterinárias Desidério Finamor (CPVDF/Fepagro), Estrada do Conde 6000, Eldorado do Sul, RS 90001-970, Brazil. Email:sbrki@zaz.com.br

The antigenic and phenotypic variation among 22 strains of Pasteurella multocida isolated from pig lungs with pneumonia and/or pleuritic lesions was studied. Phenotypic tests consisted of biochemical assays and antimicrobial sensitivity tests. All isolates fermented mannitol and sorbitol, but none fermented arabinose. Fourteen fermented xylose, 4 trehalose, 2 dulcitol and 1 maltose. Analyzing these characteristics, 5 different biochemical groups were revealed. There was a wide variation in the results of antimicrobial sensitivity testing to 9 products, with $50 \%$ of isolates showing sensitivity at least to 7 . No antimicrobial agent was able to inhibit all strains. The highest efficiency ( $72 \%$ sensitivity) was observed with amoxycillin (30 $\mathrm{mg})$. Spectinomycin $(100 \mathrm{mg}$ ) presented the lowest efficiency, $45.5 \%$. Antigenic characterization consisted in capsular serotyping and assessment of variability of an outer membrane protein gene $(\mathrm{ompH})$, using polymerase chain reaction (PCR) and digestion with 5 endonuclease enzymes (restriction fragment length polymorphism, RFLP). Out of 22 strains, 21 were classified as capsular type A and one as type D. Characterization of ompH revealed 7 different patterns. They corresponded well to previously established biochemical groups.
\end{abstract}

INDEX TERMS: Pasteurella multocida, pigs, pneumonia, pleuritis.

RESUMO.- Foi analisada a variabilidade antigênica e fenotípica de 22 cepas de Pasteurella multocida isoladas de pulmões de suínos com pneumonia e/ou pleurite. Os testes fenotípicos foram realizados pela determinação de características bioquímicas e sensibilidade a agentes antimicrobianos. Todos

\footnotetext{
${ }^{1}$ Aceito para publicação em 15 de agosto de 2001.

Parte da tese de doutorado do primeiro autor, Faculdade de Veterinária, UFRGS, Porto Alegre, RS. Trabalho financiado pela FAPERGS.

${ }^{2}$ Centro de Pesquisas Veterinárias Desidério Finamor (CPVDF/ Fepagro), Eldorado do Sul, Cx. Postal 2076, Porto Alegre, RS 90001-970. E-mail sbrki@zaz.com.br

${ }^{3}$ Simbios Biotecnologia, Canoas, RS.

${ }^{4}$ Universidade Luterana do Brasil (ULBRA), Canoas, RS.

${ }^{5}$ Universidade Federal do Rio Grande do Sul, Porto Alegre, RS.
}

os isolados fermentaram manitol e sorbitol, mas nenhum arabinose; 14 foram capazes de metabolizar xilose, quatro trealose, dois dulcitol e um maltose. A análise destas características permitiu agrupar os isolados em 5 padrões bioquímicos distintos. Quanto à sensibilidade a nove agentes antimicrobianos, verificou-se grande variação, com apenas $50 \%$ dos isolados sensíveis a pelo menos sete dos nove antibióticos testados. Nenhum princípio ativo foi capaz de inibir todos os isolados. A melhor eficiência foi observada com a amoxicilina (30 mg); $72,7 \%$ dos isolados se mostraram sensíveis. A menor eficiência foi demonstrada pela espectinomicina $(100 \mathrm{mg})$ com 45,5\%. A caracterização antigênica consistiu na sorotipagem capsular e determinação de variabilidade do gene de proteína de membrana externa $(\mathrm{ompH})$ pela reação em cadeia da polimerase (PCR) e digestão com cinco enzimas de restrição. Das 22 cepas, 21 foram compatíveis 
com sorotipo capsular A e uma com D. A caracterização do gene ompH agrupou os isolados em sete padrões distintos que apresentaram boa correlação com os testes bioquímicos.

TERMOS DE INDEXAÇÃO: Pasteurella multocida, suínos, pneumonia, pleurite.

Classificação CNPq: 5.05.02.00-0 Medicina Veterinária Preventiva.

\section{INTRODUÇÃO}

A Pasteurella multocida é um microorganismo que faz parte da flora comensal do trato respiratório superior dos suínos. Algumas cepas estão relacionadas com a rinite atrófica progressiva e outras com pleurites e pneumonias. Estas patologias são altamente contagiosas e de grande relevância econômica na suinocultura moderna (Pijoan 1992, Sobestiansky et al. 1999).

Vários métodos têm sido desenvolvidos para diferenciar cepas relacionadas com patologias do trato respiratório. Os mais utilizados se baseiam na sorotipagem de antígenos capsulares e somáticos, produção de toxina dermonecrótica, características bioquímicas e caracterização de ácidos nucléicos (Carter \& Subronto 1973, Carter \& Rundell 1975, Ahn \& Kim 1994).

A caracterização de antígenos capsulares agrupa toda a espécie em cinco sorotipos (A, B, C, D e E). Os sorotipos A, D e $B$ já foram descritos em suínos. $O$ último é atípico e confinado a regiões do sudeste da Ásia e China (Pijoan 1992). As cepas relacionadas com a rinite atrófica progressiva pertencem aos sorotipos capsulares A e D. A caracterização de cepas relacionadas com a rinite é realizada por testes que indicam a presença de toxina dermonecrótica, presente somente nas cepas patogênicas (Nagai et al. 1994, Lichtensteiger et al. 1996). Os casos de pneumonias e pleurites estão relacionados principalmente com o sorotipo A e com menor frequiência com D. Nestes casos não foi comprovada uma correlação direta entre patogenia e presença de toxina (Pijoan 1992).

Os antígenos somáticos também são utilizados para caracterização de cepas, sendo já identificados 16 sorotipos na espécie. Os grupos somáticos ocorrem com diferentes grupos capsulares Assim, é comum se referir a uma cepa utilizando-se o grupo capsular e o somático. Uma cepa do sorotipo capsular A e sorotipo somático 3 é identificada como A:3. Sabe-se que algumas composições antigênicas, como sorotipos B:2 e E:2 estão relacionadas com septicemias hemorrágicas em bovinos na Ásia e África (Wilson et al. 1992). Em suínos as composições antigênicas mais freqüentemente encontradas em pulmões com pneumonias, em ordem de prevalência são A:3, A:5, D:5 e D:3 (Pijoan 1992).

Outro enfoque, relacionado com a caracterização antigênica foi realizado por Luo et al. $(1997,1999)$. Estes autores caracterizaram uma porina denominada proteína $\mathrm{H}$ ou porina $\mathrm{H}$ de 15 sorotipos somáticos de P. multocida. Este antígeno consiste de uma proteína majoritária de membrana externa (major outer membrane protein $\mathrm{H}-\mathrm{ompH}$ ), que forma canais que atravessam a membrana celular. As porinas se caracterizam por serem altamente imunogênicas e capazes de induzir proteção em modelos animais. A caracterização de sequiências de $o m p H$ de 15 sorotipos somáticos de $P$. multocida revelaram regiões com alto grau de identidade, com variações confinadas a duas regiões correspondentes a alças externas da proteína (regiões hipervariáveis). Estas se mostraram bastante polimórficas entre os diferentes sorotipos estudados.

Autores têm agrupado cepas de P. multocida com base em diferenças de comportamento nas reações bioquímicas (Rimler \& Rhoades 1989). Essa classificação considera principalmente características como a produção de ácido a partir de determinadas pentoses (como xilose e arabinose), dissacarídeos (como maltose e trealose) e álcoois polihídricos (como sorbitol, manitol e dulcitol). Rosenbusch \& Merchant (1939) classificaram isolados de $P$. multocida em três grupos em função da fermentação de xilose, arabinose e dulcitol. $O$ grupo I fermentou arabinose e dulcitol mas não xilose, o grupo II fermentou xilose mas não arabinose ou dulcitol e o grupo III apresentou padrão variável, mais próximo ao grupo I.

A caracterização de sensibilidade a antibióticos não tem sido freqüentemente utilizada para fins taxonômicos, mas para direcionamento de uma terapia mais eficiente com antimicrobianos. Penicilinas, oxitetraciclinas, sulfonamidas e sulfametazina têm sido utilizadas no controle de infecções causadas pela P. multocida. Distintos dos isolados humanos, os encontrados em suínos são normalmente resistentes a muitos destes antibióticos (Holmes et al. 1999).

Métodos baseados na análise de ácidos nucléicos têm sido aplicados na diferenciação de $P$. multocida. A caracterização de perfil de ácidos nucléicos digeridos com restrição (DNA fingerprint) foi utilizada para diferenciar 16 sorotipos somáticos por Wilson et al. (1992). Além destas amostras, os autores caracterizaram 84 isolados relacionados com casos clássicos de septicemias hemorrágicas em bovinos. Foi demonstrado ainda que os padrões de restrição apresentaram boa correlação com os sorotipos somáticos estudados.

Mogollon et al. (1998), avaliaram isolados do sorotipo capsular A de suínos com pneumonia e os diferenciaram em cinco grupos, indicando que mais de um padrão foi encontrado simultaneamente numa mesma granja. A limitação desta técnica é a necessidade de amostras isoladas em grandes quantidades, não sendo possível a análise direta a partir das amostras clínicas. Assim, técnicas como a reação em cadeia da polimerase (PCR) têm sido desenvolvidas para este fim. Existem trabalhos que diferenciam cepas produtoras de toxina dermonecrótica relacionadas com a rinite atrófica (Nagai et al. 1994, Kamp et al. 1996, Lichtensteiger et al. 1996). Uma outra metodologia foi desenvolvida por Zucker et al. (1996) capaz de diferenciar cepas de mesmo sorotipo capsular pela reação em cadeia da polimerase utilizando primers arbitrários (AP-PCR). Neste trabalho foram analisados 44 isolados do trato respiratório de suínos que puderam ser identificados em sete grupos. $\mathrm{O}$ inconveniente do AP-PCR é a necessidade de amostras isoladas, já que há grande interferência na especificidade do teste em presença de ácidos nucléicos, como o do hospedeiro.

O presente trabalho teve como objetivo a caracterização 
antigênica, fisiológica e genética de 22 amostras de $P$. multocida isoladas de pulmões de suínos com pneumonia e/ ou pleurite no Rio Grande do Sul. A verificação da diversidade entre os isolados foi feita pela caracterização de sorotipos capsulares, perfil bioquímico, sensibilidade a antimicrobianos e diferenciação genética do antígeno de $o m p H$.

\section{MATERIAL E MÉTODOS}

\section{Cepas}

Foram utilizadas no presente estudo 22 cepas de Pasteurella multocida isoladas em diferentes locais e três cepas de referência. Dez cepas foram isoladas de pulmões de suínos abatidos em quatro frigoríficos do Estado do Rio Grande do Sul e identificadas como PI5, PI21, PI7, FII14, PIII47, PII8, PIII19, FII9, PIII43, CII2 (Stepan 1995). Doze isolados foram obtidos a partir cultivos de pulmões colhidos de leitões com pneumonia e/ou pleurite no Laboratório de Patologia Suína do Centro de Pesquisa Veterinária Desidério Finamor, CPVDF/ Fepagro, Eldorado do Sul, RS, e identificados como 76, 805, Ta, 710, FR, 1/95, 1265, 1133, 903, 1628, 1363 e 1621 . Duas cepas de referência do sorotipo capsular D (TCD e FIMB D) e uma do sorotipo capsular A (CR) foram também utilizadas. A cepa TCD foi obtida da American Type Culture Collection (ATCC $\mathrm{n}^{0}$ 12948) e as cepas FIMBD e CR no Centro Nacional de Pesquisa em Suínos e Aves, CNPSA/Embrapa, Concórdia, SC.

As bactérias foram cultivadas em meio infuso cérebro e coração (BHI) adicionado de $5 \%$ de soro eqüino. Os isolados foram mantidos sob liofilização até o seu uso para as diferentes provas de classificação.

\section{Sorotipificação com antígeno capsular}

As amostras foram classificadas com base nos antígenos capsulares A e D. Empregou-se o teste de acriflavina neutra 1:1000 (Carter \& Subronto 1973) para a caracaterização das cepas tipo D. O teste de hialuronidase, descrito em Carter \& Rundell (1975), foi empregado para a identificação das cepas do tipo A, utilizando-se uma cepa de Staphylococcus aureus produtora de hialuronidase.

\section{Caracterízação bioquímica}

As técnicas utilizadas para a realização das provas bioquímicas foram as descritas por Cowan (1975). Foram realizados testes de utilização dos seguintes substratos: xilose, arabinose, maltose, trealose, sorbitol, manitol e dulcitol.

Colônias puras de cada amostra crescidas por 18 horas em meio ágar sangue foram inoculadas em tubos contendo $3 \mathrm{ml}$ de cada substrato e incubadas por $24 \mathrm{~h} \mathrm{a} 37^{\circ} \mathrm{C}$. Após este período foi realizada a leitura.

\section{Sensibilidade a antimicrobianos}

A sensibilidade in vitro das amostras de $P$. multocida frente aos antimicrobianos foi determinada pela técnica de difusão em discos em ágar Müller Hinton (Bauer \& Kirby 1966).

As amostras foram testadas frente aos seguintes antimicrobianos, nas concentrações indicadas: amoxicilina $(30 \mathrm{mg})$; oxitetraciclina (30 $\mathrm{mg})$; ceftiofur (30 mg); tilmicosina (15 mg); enrofloxacina (5 mg); espectinomicina (100 mg); canamicina (30 mg); sulfa/trimetoprima (25 mg) e neomicina (35 mg). A leitura foi realizada 24 h após e os resultados foram interpretados seguindo instruções dos fabricantes.

\section{Análise de sequiências de ompH}

Foram obtidas sequiências de nucleotídeos do gene $o m p H$ de $P$. multocida disponíveis no banco de dados Genbank (números de acesso
U50907, U52200 a U52213). O alinhamento de todas as sequiências foi obtido em um programa de computador Clustal-W 1.6 (European Molecular Biology Laboratory, Alemanha). Um par de primers com seqüiências conservadas entre os sorotipos somáticos foi desenhado usando um software de análise de primers (Oligo ${ }^{\mathrm{TM}}$, National Biosciences, Plymouth, Minnesota, EUA).

\section{Extração de DNA}

Foi extraído DNA total de cada amostra de $P$. multocida pela técnica fenol/clorofórmio (Sambrook et al. 1989). Resumidamente, as bactérias foram concentradas por centrifugação (12.000 x g por 2 min.), lavadas em salina fosfatada tamponada e suspensas em 400 $\mathrm{ml}$ de água destilada. Adicionou-se $100 \mathrm{ml}$ de solução de sódio dodecil sulfato 5\% (Sigma), $20 \mathrm{mg}$ de proteinase K (Sigma) e EDTA 50 $\mathrm{mM}$, seguindo-se a incubação por $10 \mathrm{~min}$ a $37^{\circ} \mathrm{C}$. A extração foi realizada com fenol e clorofórmio: álcool isoamílico (24:1); posteriormente o DNA foi precipitado usando isopropanol, lavado com etanol $70 \%$ e ressuspendido em $50 \mathrm{ml}$ de água destilada.

\section{Condições de reação em cadeia da polimerase}

DNA das cepas de referência e dos isolados (10-20 hg) foram amplificados de acordo com as recomendações do fabricante (Cenbiot Enzimas, Centro de Biotecnologia, RS), como segue: volume de reação $50 \mathrm{ml}, 1,5 \mathrm{U}$ de Taq polimerase, $0,25 \mathrm{mM}$ de dNTPs, $25 \mathrm{rmol}$ de cada primer, 1,5 mM MgCl2 e tampão de reação fornecido pelo fabricante.

A amplificação foi realizada com um ciclo de desnaturação a $94^{\circ} \mathrm{C}$ por três minutos, seguido por 40 ciclos com desnaturação $\left(94^{\circ} \mathrm{C}\right)$ por 30 segundos, anelamento $\left(60^{\circ} \mathrm{C}\right)$ por 40 segundos e extensão $\left(72^{\circ} \mathrm{C}\right)$ por 60 segundos. Após os 40 ciclos realizou-se extensão final $\left(72^{\circ} \mathrm{C}\right)$ por cinco minutos. Após a amplificação, as amostras foram analisadas em gel de agarose $2 \%$ corado com brometo de etídio.

\section{Análise do polimorfismo pela digestão por enzima de restrição de ompH}

Os produtos amplificados foram digeridos com as enzimas de restrição Alu I, Sau3A I, Dde I, Hinf I e Rsa I (Amersham) de acordo com as instruções do fabricante. Os fragmentos digeridos foram visualizados após separação por eletroforese em gel de poliacrilamida $(12,5 \%)$ e corados com nitrato de prata (Sanguinetti et al. 1994).

\section{RESULTADOS}

As cepas de referência apresentaram resultados da determinação do sorotipo capsular compatíveis com o esperado: TCD e FIMBD pertencentes ao tipo capsular D e CR tipo capsular A. Dos 22 isolados de campo, somente a cepa 1/95 se mostrou compatível com sorotipo D. Os demais isolados apresentaram resultados compatíveis com o tipo capsular A. Os resultados dos testes bioquímicos estão descritos no Quadro 1. Dentre os isolados analisados, todos foram capazes de metabolizar manitol e sorbitol. Nenhum foi capaz de metabolizar arabinose. Quanto aos demais substratos houve uma variabilidade na capacidade de metabolização dentre os isolados: $14(63,6 \%)$ foram capazes de metabolizar xilose, quatro $(18,2 \%)$ trealose, dois $(9,1 \%)$ dulcitol e um $(4,5 \%)$ maltose. Em função do perfil fenotípico os isolados foram divididos em cinco padrões (Quadro 1).

Os resultados do teste de sensibilidade aos antimicrobianos estão descritos nos Quadros 2 e 3 . Houve grande variação quanto ao padrão de sensibilidade, não sendo observado nenhum princípio ativo capaz de inibir todos os isolados 
Quadro 1. Resultados dos testes bioquímicos a partir das cepas de P. multocida estudadas

\begin{tabular}{lcccccccc}
\hline \multicolumn{1}{c}{ Cepas } & Man & Sor & Arab & Mal & Dul & Xil & Tre & $\begin{array}{c}\text { Perfil fe- } \\
\text { notípico }\end{array}$ \\
\hline 1133, FII14, Ta, 710 & & & & & & & & \\
PI21, FR, 805, 1363, 76 & $+{ }^{\mathrm{b}}$ & + & - & - & - & + & + & I \\
PI5, PI7 & + & + & - & - & - & - & - & II \\
PII8, 1628, FII9, 1265 CII2, 1/95, & + & + & - & - & - & + & - & IV \\
PIII43, PIII19, PIII47, 1621 & + & + & - & - & + & - & - & III \\
903 & + & + & - & + & - & - & - & V \\
FIMB D & + & + & - & - & - & + & - & IV \\
TCD & + & + & - & - & - & + & - & \\
CR & + & + & - & - & - & + & - & \\
\end{tabular}

${ }^{\mathrm{a}} \mathrm{Xil}=$ xilose, $\mathrm{arab}=$ arabinose, mal $=$ maltose, tre $=$ trealose, sor $=$ sorbitol, man $=$ manitol, dul $=$ dulcitol.

$\mathrm{b}_{+}=$utilização do substrato, com viragem do indicador; - = sem utilização.

Quadro 2. Resultados do teste de sensibilidade apresentado pela cepas de Pasteurella multocida frente a nove antimicrobianos

\begin{tabular}{lccccccccc}
\hline Cepas & AMO $^{\mathrm{a}}$ & XNL & TIL & SUT & EN & NE & OXT & KN & ET \\
\hline 1133 & S & S & S & S & S & S & S & S & S \\
FII14 & I & S & S & R & S & S & S & S & I \\
Ta & S & S & S & S & S & S & S & S & I \\
710 & S & S & S & I & S & R & S & I & R \\
PI21 & I & R & I & R & R & I & S & I & S \\
FR & S & S & S & S & S & R & S & R & S \\
805 & S & S & S & S & S & R & R & S & S \\
1363 & S & I & I & I & R & R & I & R & R \\
76 & S & S & S & S & S & S & S & S & R \\
PI5 & S & I & I & I & I & S & I & I & R \\
PI7 & S & S & I & S & R & R & R & R & R \\
PII8 & S & S & S & S & I & S & S & S & S \\
1628 & I & R & S & S & R & S & I & S & R \\
FII9 & S & S & S & S & S & I & R & S & S \\
1265 & S & S & S & S & S & S & R & S & S \\
CII2 & S & S & S & S & S & S & S & S & I \\
$1 / 95$ & S & S & S & S & S & S & I & S & S \\
PIII43 & S & I & I & I & I & S & S & I & R \\
PIII19 & S & S & S & S & S & S & S & S & S \\
PIII47 & R & R & S & I & I & I & I & I & S \\
1621 & I & R & R & S & R & R & I & R & R \\
903 & R & S & I & R & R & R & I & I & R
\end{tabular}

aAMO (amoxicilina $30 \mu \mathrm{g}$ ), XNL (ceftiofur $30 \mu \mathrm{g}$ ), TIL (tilmicosina $15 \mu \mathrm{g}$ ), SUT (sulfa/ trimetoprima $25 \mu \mathrm{g}$ ), EN (enrofloxacina $5 \mu \mathrm{g}$ ), NE (neomicina $35 \mu \mathrm{g}$ ), OXT (oxitetraciclina $30 \mu \mathrm{g}$ ), KN (canamicina $30 \mu \mathrm{g}$ ), ET (espectinomicina $100 \mu \mathrm{g}$ ).

bS = sensível), $\mathrm{R}=$ resistente, $\mathrm{I}=$ intermediário.

(Quadro 3). O antimicrobiano que apresentou maior percentual de sensibilidade foi a amoxicilina, para a qual $72,7 \%$ dos isolados foram sensíveis. A espectinomicina foi o que apresentou o menor número de isolados sensíveis $(45,5 \%)$. $O$ perfil de sensibilidade dos isolados demonstrou que alguns foram mais sensíveis a um maior número de antimicrobianos testados.

Baseados no trabalho de Luo et al. (1997), 15 sequiências de $o m p H$, pertencentes a 15 sorotipos somáticos foram avaliadas para desenho e síntese de primers. A localização dos primers é relativa a uma região conservada deste gene, e se encontram entre as posições 546-567 (Past-3F 5'TKGATAAYGGTTCACGCGTTTC-3') e 1145-1169 (Past-4R 5'-CGT
AGT CAA CAC CWA GYG CTA AAC C-3') da cepa X-73 (código de acesso U50907). Analisando-se estas sequiências, observou-se deleções e/ou inserções que faziam com que os fragmentos de ompH apresentassem diferentes pesos moleculares. Os fragmentos delimitados entre os primers Past $3 \mathrm{~F}$ e Past 4R, variaram de 582 bp para o sorotipo somático 11 (código de acesso U52208) à 624 bp para a cepa X73 (código de acesso U50907).

As cepas de referência e todos os isolados foram submetidos à amplificação de $o m p H$ com os primers Past 3F e Past 4R. Houve amplificação de todas as amostras do estudo, com tamanho de fragmentos compatíveis com peso molecular esperado (entre 580 a $640 \mathrm{bp}$, confirmados por sequenciamento). Estes dados demonstram que a sequiência de $o m p H$ foi conservada entre todos os isolados de suínos analisados neste trabalho. Além disso, foi demonstrado que este gene foi conservado entre cepas do sorotipo capsular analisado A e D. As cepas de referência TCD e FIMBD e o isolado 1/95 são pertencentes ao tipo capsular D, enquanto que a cepa de referência CR e todos os demais isolados pertencem ao tipo capsular A. Analisando-se os sítios de restrição polimórficos em ompH do Genbank, foram escolhidas enzimas de restrição Alu I, Sau3A I, Dde I, Hinf I e $R s a$ I para análise de RFLP (polimorfismo de comprimento dos fragmentos de restrição). Assim, os fragmentos amplificados foram posteriormente digeridos com estas enzimas e analisados em gel de poliacrilamida corado com nitrato de prata. Nas Figuras 1 e 2 e no Quadro 3 estão apresentados estes resultados.

Quadro 3. Porcentagem das 22 cepas de Pasteurella multocida sensíveis, resistentes e com sensibilidade intermediária testadas frente a nove antimicrobianos

\begin{tabular}{lccccccccc}
\hline & AMO $^{\mathrm{a}}$ & XNL & TIL & SUT & EN & NE & OXT & KN & ET \\
\hline Sensível & 72,7 & 68,2 & 68,2 & 63,6 & 54,5 & 54,5 & 50,0 & 54,5 & 45,5 \\
Intermediário & 18,2 & 13,6 & 27,3 & 22,7 & 18,2 & 13,6 & 31,8 & 27,3 & 13,6 \\
Resistente & 9,1 & 18,2 & 4,5 & 13,6 & 27,3 & 31,8 & 18,2 & 18,2 & 40,9
\end{tabular}

${ }^{a}$ AMO (amoxicilina $30 \mu \mathrm{g}$ ), XNL (ceftiofur $30 \mu \mathrm{g}$ ), TIL (tilmicosina $15 \mu \mathrm{g}$ ), SUT (sulfa/trimetoprima $25 \mu \mathrm{g}$ ), EN (enrofloxacina $5 \mu \mathrm{g}$ ), NE (neomicina $35 \mu \mathrm{g}$ ), OXT (oxitetraciclina $30 \mu \mathrm{g}$ ), KN (canamicina $30 \mu \mathrm{g}$ ), ET (espectinomicina $100 \mu \mathrm{g}$ ). 


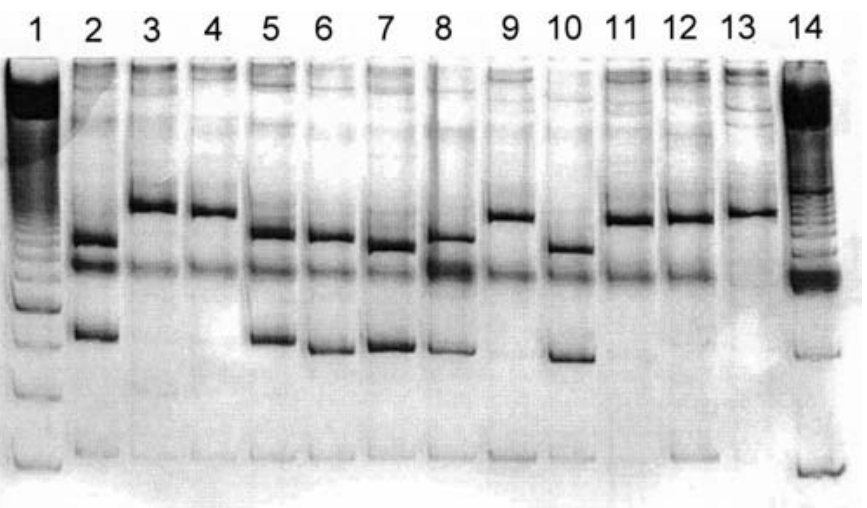

Fig. 1. Eletroforese em gel de poliacrilamida $12,5 \%$ corado com nitrato de prata. Produtos de amplificação do gene $\mathrm{ompH}$ digeridos com a enzima de restrição Hinf I. Canaletas 1 e 14: pesos moleculares de 50 e $100 \mathrm{bp}$, respectivamente. Canaleta 13: amostra TCD intacta. Entre as canaletas 2 a 12 sequencialmente encontram-se os isolados 1628, PII 8, FII 14, 903, PI 7, CR, PI 5, TCD, 1/95, FIMB D e 1265.

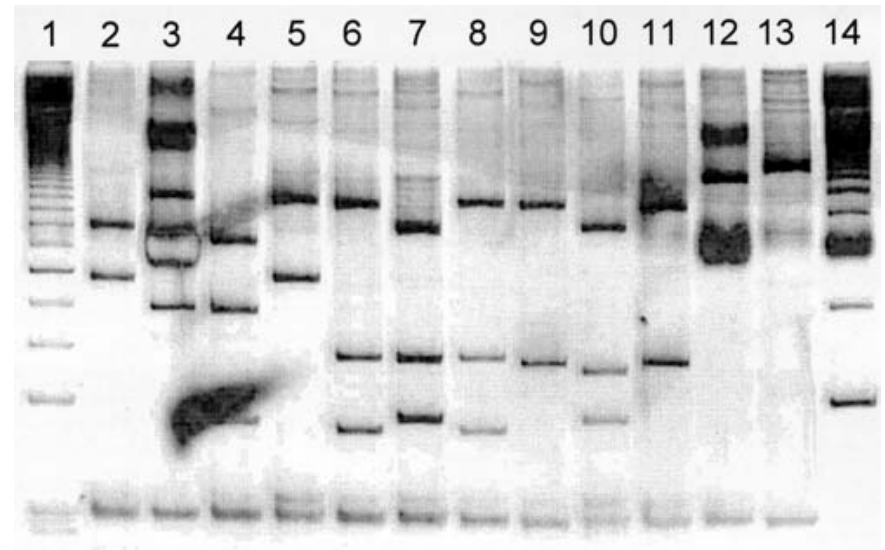

Fig. 2. Eletroforese em gel de poliacrilamida $12,5 \%$ corado com nitrato de prata. Produtos de amplificação do gene $o m p H$ digeridos com a enzima de restrição Rsa I. Canaletas 1 e 14: pesos moleculares de 50 e $100 \mathrm{bp}$, respectivamente. Canaleta 13: amostra TCD intacta. Entre as canaletas 2 a 12 sequencialmente encontram-se os isolados 1628, PII 8, FII 14, 903, PI 7, CR, PI 5, TCD, 1/95, FIMB D e 1265.

Quadro 4. Padrões de restrição obtidos pela digestão de ompH com enzimas de restrição Alu I, Sau 3A I, Dde I, Hinf I e Rsa I. Os pesos moleculares dos fragmentos foram estimados em gel de poliacrilamida e as amostras em negrito utilizadas seqüenciadas para confirmação dos pesos moleculares e sítios de restrição

\begin{tabular}{|c|c|c|c|c|c|c|c|c|}
\hline Cepas & Intacto & Alu I & Sau3A I & Dde I & $\operatorname{Hinf} \mathrm{I}$ & Rsa I & $\mathrm{PF}^{\mathrm{a}}$ & GM \\
\hline 1628,1621 & 601 & $55 / 531$ & 601 & 39/255/99/208 & $206 / 395$ & $228 / 330 / 43$ & IV & 1 \\
\hline PII8, CII2, PIII19, PIII47, FII9, PIII43 & 607 & $490 / 117$ & 607 & $39 / 216 / 261 / 91$ & 607 & $189 / 418$ & IV & 2 \\
\hline 1133, FII14, Ta, 710 & 607 & $550 / 57$ & 607 & $39 / 315 / 143 / 110$ & 607 & $186 / 86 / 305 / 30$ & I & 3 \\
\hline $903,805,1363,76$, FR, PI21 & 640 & $64 / 519 / 58$ & 640 & $599 / 41$ & $203 / 437$ & $225 / 415$ & $\mathrm{~V}, \mathrm{II}$, & 4 \\
\hline PI7, PI5 & 615 & 615 & $115 / 500$ & 615 & $430 / 185$ & $405 / 130 / 80$ & III & 5 \\
\hline 125 & 589 & $64 / 468 / 57$ & 589 & 39/243/99//208 & 589 & $546 / 43$ & III & 6 \\
\hline $1 / 95, C R$ & 586 & $64 / 522$ & 586 & $38 / 336 / 211$ & $188 / 398$ & $87 / 123 / 333 / 43$ & IV & 7 \\
\hline TCD, FIMBD & 580 & $64 / 516$ & 580 & 39/240/99/202 & 580 & $131 / 406 / 43$ & IV & 8 \\
\hline
\end{tabular}

apF = perfil fenotípico; $\mathrm{GM}=$ grupo molecular.

Conforme esperado na análise de sequiências, o gene $\mathrm{ompH}$ se mostrou bastante eficiente quanto à identificação de polimorfismos entre os isolados de $P$. multocida. A determinação exata dos pesos moleculares e dos sítios de restrição (Quadro 3) foi realizada pelo sequenciamento dos produtos de amplificação de algumas das amostras.

\section{DISCUSSÃO}

Das 22 amostras de P. multocida no presente estudo somente $o$ isolado 1/95 foi classificado como sorotipo capsular D. Estes resultados foram similares aos encontrados por outros autores (Pijoan et al. 1983, Iwamatsu \& Sawada 1988, Lopez et al. 1988, Awad-Masalmeh et al. 1994), o que reforça a afirmação de Rutter (1983), Pijoan (1992) e Zhao et al. (1992) de que as cepas do sorotipo $\mathrm{A}$ são mais freqüientes de serem encontradas em processos pneumônicos. A predominância das cepas do sorotipo A pode estar relacionada com a capacidade de aderência às células epiteliais, tornando-as capazes de se espalhar pelas vias aéreas sem serem eliminadas pelo mecanismo mucociliar (Glorioso et al. 1982). No pulmão estaria relacionada com a presença da cápsula de ácido hialurônico, que dificultaria a fagocitose pelos macrófagos alveolares (Pijoan 1992). Foi realizada também a identificação de cepa toxigênica pela técnica de PCR destas amostras (dados não demonstrados no presente estudo). Somente a cepa 1/95 apresentou compatibilidade como cepa com toxina dermonecrótica. A baixa frequiência de cepas toxigênicas relacionadas com processos pneumônicos encontrada neste trabalho corrobora os dados de Pijoan (1992), que identificou também cepas toxigênicas em amostras de lesões nos pulmões $\mathrm{O}$ autor menciona que esta característica não era definitiva para identificar a patogenicidade das cepas, como ocorre nos casos de rinite atrófica progressiva.

Os resultados dos testes bioquímicos obtidos neste estudo (Quadro 1) foram semelhantes aos observados por Heddleston (1976). O autor, ao analisar 67 amostras de $P$. multocida isoladas de suínos constatou que nenhuma foi positiva para os testes de utilização da arabinose, maltose e 
dulcitol . Observações coincidentes também foram obtidas com relação aos testes de utilização do manitol, sorbitol, trealose e xilose. No presente trabalho observou-se que o uso da xilose, trealose, dulcitol e maltose permitiu a diferenciação das cepas e a discriminação em cinco grupos distintos. A fermentação do sorbitol e manitol em todas as cepas está de acordo com a definição de $P$. multocida subsp. multocida (Mutters et al. 1989).

Quanto aos antimicrobianos testados foi observada uma grande diferença de sensibilidade entre os isolados. Nenhum princípio ativo testado mostrou ser eficiente para todas as amostras. A porcentagem de isolados sensíveis aos antimicrobianos variou de $45,5 \%$ (espectinomicina) a $72,5 \%$ (amoxicilina). Quanto à resistência múltipla a antimicrobianos, observou-se que $36,4 \%$ dos isolados eram sensíveis a um máximo de três antimicrobianos, $13,6 \%$ sensíveis de quatro a seis antimicrobianos e $50 \%$ a pelo menos sete antimicrobianos. Estes dados alertam para a seleção de isolados resistentes aos antibióticos utilizados nas granjas, e da necessidade de um uso menos indiscriminado destes medicamentos para que a terapêutica continue com resultados satisfatórios. A classificação por padrão de sensibilidade a antimicrobianos não parece ser muito adequada para fins de caracterização devido a grande variabilidade de padrões existentes, mas sugere que seja recomendável a realização de testes de sensibilidade in vitro antes de iniciar um tratamento.

Segundo Zhao et al. (1992), o microorganismo está disseminado nas granjas de suínos e estudos epidemiológicos mais aprofundados têm sido dificultados pela falta de um método discriminatório apropriado, o qual poderia identificar amostras individuais associadas com a doença dentro de um determinado sorotipo ou diferenciar cepas virulentas em populações de suínos. Rúbies et al. (1996) ressaltam que as técnicas fenotípicas convencionais como sorotipagem, biotipagem, determinação da sensibilidade a antimicrobianos e fagotipagem não são suficientemente sensíveis para diferenciar clones individuais envolvidos em surtos naturais.

Métodos moleculares, como a digestão do DNA genômico bacteriano utilizando enzimas de restrição, prometem ser melhores alternativas aos métodos taxonômicos, sendo consideradas valiosas ferramentas no estudo epidemiológico das enfermidades infecciosas. Segundo Valenzuela et al. (1995), esses métodos permitem estabelecer uma relação clonal entre cepas isoladas em diferentes situações epidemiológicas e facilitam o estudo da história natural das enfermidades. Por outro lado, técnicas descritas como a reação em cadeia da polimerase, têm possibilitado um diagnóstico específico e rápido, como no caso da identificação de cepas toxigênicas de $P$. multocida em casos de rinite atrófica progressiva. Ainda não é conhecida uma informação tão precisa no diagnóstico de cepas relacionadas com processos pneumônicos. Nestes casos, procura-se primeiramente isolar a bactéria de lesões pulmonares com posterior caracterização antigênica, bioquímica ou molecular. Essa análise poderia fornecer subsídios para verificar a possível existência de vários clones bacterianos numa mesma granja ou região e o relacionamento clonal de cepas isoladas de diferentes regiões ou propriedades.
$O$ presente trabalho procurou acoplar o ganho de sensibilidade do PCR com a utilização de enzimas de restrição de um gene que sabidamente apresenta polimorfismo nos casos de cepas relacionadas com processos pneumônicos. $\mathrm{O}$ gene ompH, descrito por Luo et al. (1997, 1999), além de apresentar polimorfismo entre diferentes sorotipos somáticos, está envolvido em diferenças antigênicas entre cepas que têm sido estudadas para o desenvolvimento de vacinas mais eficientes. Foram desenhados primers em regiões conservadas entre os diferentes sorotipos, e que flanqueavam as regiões hipervariáveis de $o m p H$. Os primers foram eficientes para amplificar todos os isolados e cepas de referência, confirmando que a região escolhida é conservada para amostras isoladas de suínos. A utilização de cinco enzimas de restrição agrupou os 22 isolados em sete grupos moleculares (além de um outro grupo, o 8, onde se agruparam as cepas controles do tipo capsular D, TCD e FIMBD).

Com relação à origem das amostras em estudo, aquelas isoladas de casos clínicos foram enquadradas em cinco grupos. Com as amostras isoladas de frigorífico também observou-se uma tendência à concentração em grupos distintos. No grupo 2, 87,5\% dos isolados foram de frigorífico, enquanto que no grupo cinco todos tiveram a mesma origem.

Observou-se em alguns casos concordância entre os grupos estabelecidos pelos testes bioquímicos e os grupos moleculares. Nos grupos 1 , 3 e 5 houve $100 \%$ de concordância entre as duas provas; no grupo $4,83 \%$. Esses resultados sugerem que a análise fenotípica baseada na utilização de pentoses, dissacarídeos e álcoois poderia ser usada como triagem para estabelecer diferenças clonais (subtipagem) entre determinadas amostras de $P$. multocida.

\section{REFERÊNCIAS}

Ahn B.C. \& Kim B.H. 1994. Toxigenicity and capsular serotypes of Pasteurella multocida isolated from pneumonic lungs of slaughter pigs, p. 165. In: Proc. 13th Int. Pig Veterinary Society Congress, Thailand.

Awad-Masalmeh M., Kourouma G., Köfer J. \& Schuh M. 1994. Investigations on Pasteurella multocida lesions of slaughter swine suffering from chronic respiratory disorders, p.172. In: Proc. 13th Int. Pig Veterinary Society Congress, Thailand.

Bauer A. M. \& Kirby W.M.M. 1966. Antibiotic susceptibility by standartized single disc method. Am. J. Clin. Path. 45:493- 496.

Carter G.R. \& Subronto P. 1973. Identification of type D strains of Pasteurella multocida with acriflavine. Am. J. Vet. Res. 34:293-294.

Carter G.R. \& Rundell D.W. 1975. Identification of type A strains of Pasteurella multocida using staphylococcal hyaluronidase. Vet.Rec. 87:343.

Cowan S.T. 1975. Manual for the identification of medical bacteria. 2nd ed. Cambridge University Press, Cambridge. 238 p.

Glorioso J.C., Jones G.W. \& Rush, H.G. 1982. Adhesion of type A Pasteurella multocida to rabbit pharyngeal cells and its possible role in rabbit respiratory tract infections. Infect. Immun. 35:1105-1109.

Heddleston K.L. 1976. Physiologic characteristics of 1,268 cultures of Pasteurella multocida. Am. J. Vet. Res. 37:6.

Holmes B., Pickett M.J. \& Hollis D.G. 1999. In: Manual of Clinical Microbiology. 7th ed. American Society of Microbiolgy, New York. p. 632-637.

Iwamatsu S. \& Sawada T. 1988. Relationship between serotypes, dermonecrotic toxin production of Pasteurella multocida isolates and pneumonic lesions of porcine lung. Jpn. J. Vet. Sci. 50(6):1200-1206.

Kamp E.M., Bokken G.C.A.M, Vermeulen T.M.M., Jong M.F., Buys H.E.C.M, Reek, 
F.H. \& Smits M.A. 1996. A specific and sensitive PCR assay suitable for largescale detection of toxigenic Pasteurella multocida in nasal and tonsillar swabs specimens of pigs. J. Vet. Diagn. Invest. 8:304-309.

Lichtensteiger C.A., Steenbergen S.M., Lee, R.M., Polson D.D. \& Vimr E.R. 1996. Direct PCR analysis for toxigenic Pasteurella multocida. J. Clin. Microbiol. 34:3035-3039.

Lopéz A.G., Polanco J., Mora Y.P. \& Ponte F.M. 1988. Tipos capsulares A y D em cepas de Pasteurella multocida de origen porcina. Revta Fac. Ciencias Vet. 35(1-4):21-28.

Luo Y. , Zeng Q., Glisson J.R., Jackwood M.W., Hancock R.E.W., Bains M., Cheng I.H. \& Wang C. 1997. Cloning and characterization of the major outer membrane protein gene (ompH) of Pasteurella multocida X-73. J. Bacteriol. 179:7856-7864.

Luo Y., Zeng Q., Glisson J.R., Jackwood, M.W., Cheng, I.H. \& Weng C. 1999. Sequence analysis of Pasteurella multocida major outer membrane protein $(\mathrm{OmpH})$ and application of synthetic peptides in vaccination of chickens against homologous strain challenge. Vaccine 26:821-831.

Mogollon J.D., Leon A. \& Ariza F. 1998. Comparison of DNA fingerprints Pasteurella multocida type A pneumonic isolates, p. 294. In: Proc. 15th Int. Pig Veterinary Society Congress, Birmingham, England.

Mutters R., Mannheim W. \& Bisgaard M. 1989. Taxonomy of the Group, p. 334. In: Adlam C.\& Rutter J.M. (ed.) Pasteurella and Pasteurellosis. Academic Press, London.

Nagai S., Someno S. \& Yagihashi T. 1994. Differentiation of toxigenic from nontoxigenic isolates of Pasteurella multocida by PCR. J. Clin. Microbiol. 32:4.

Pijoan C. 1992. Pneumonic pasteurellosis, p. 552-559. In: Leman A. (ed.) Diseases of Swine. 7th ed. Wolfe Publishing, Iowa.

Pijoan C., Morrison R.B.\& Hilley H.D. 1983. Serotyping of Pasteurella multocida isolated from swine lungs collected at slaughter. J. Clin. Microbiol. 17(6):1074-1076.

Rhimler R.B.\& Rhoades K.R. 1989. Pasteurella multocida, p. 37-73. In: Adlam C. $\&$ Rutter J.M. (ed.) Pasteurella and Pasteurellosis, Academic Press, London.
Rosenbusch C. \& Merchant I.A. 1939. A study of the hemorrhagic septicemia Pasteurellae. J. Bacteriol. 37:69-89.

Rúbies X., Casal J., Fernandez J. \& Pijoan C. 1996. Transmission of Pasteurella multocida clones in a swine pyramid structure, p. 243. In: Proc. 14th Int. Pig Veterinary Society Congress, Bologna, Italy.

Rutter J.M. 1983. Virulence of Pasteurella multocida in athrophic rhinitis of gnotobiotic pigs infected with Bordetella bronchiseptica. Res. Vet. Sci. 34:285287.

Sambrook J., Fritsch E.F. \& Maniatis T. 1989. Molecular Cloning: A Laboratory Manual, 2nd ed. Cold Spring Harbor Laboratory, Cold Spring Harbor.

Sanguinetti C.J., Dias-Neto E. \& Simpson A.J.G. 1994. Rapid silver staining and recover of PCR products separated on polyacrylamide gels. Biotech. 17:915-919.

Sobestiansky J., Barcellos D., Mores N., Carvalho L.F. \& Oliveira S. 1999. Clínica e Patologia Suína. $2^{\mathrm{a}}$ ed., Art 3. Impressos Especiais, Goiânia.

Stepan A.L. 1995. Tipificação e sensibilidade de amostras de Pasteurella multocida isoladas a partir de lesões de pleurite em suínos terminados. Dissertação de Mestrado, Fac. Veterinária, UFRGS, Porto Alegre. 72p.

Valenzuela S., Mojica S., Ariza F. \& Mogollón J.D. 1995. Epidemiologia molecular: aplicaciones em el estudio de las enfermedades infecciosas de tipo bacteriano. Revista del Centro de Investigacion em Salud y Produccion Animal 2(1):14-28.

Wilson M.A., Rimler R.B. \& Hoffman L.J. 1992. Comparasion of DNA fingerprints and somatic serotypes of serogroup B and E Pasteurella multocida isolates. J. Clin. Microbiol. 30(6):1518-1524.

Zhao G., Pijoan C. \& Murtaugh M.P. 1992. Epidemiology of Pasteurella multocida in a farrow-to-finish swine herd, p. 157. In: Proc. 16th Int. Pig Veterinary Society Congress, Netherlands.

Zucker B., Krüger M. \& Horsch F. 1996. Differentiation of Pasteurella multocida subspecies multocida isolates from the respiratory system of pigs by using polymerase chain reaction fingerprinting technique. J. Vet. Med. 43:585591. 